\title{
Loss of protein tyrosine phosphatase, non- receptor type 2 is associated with activation of AKT and tamoxifen resistance in breast cancer
}

Elin Karlsson, Cynthia Veenstra, Shad Emin, Chhanda Dutta, Gizeh Perez-Tenorio, Bo

Nordenskjöld, Tommy Fornander and Olle Stål

\section{Linköping University Post Print}

\section{Tweet}

N.B.: When citing this work, cite the original article.

The original publication is available at www.springerlink.com:

Elin Karlsson, Cynthia Veenstra, Shad Emin, Chhanda Dutta, Gizeh Perez-Tenorio, Bo Nordenskjöld, Tommy Fornander and Olle Stål, Loss of protein tyrosine phosphatase, nonreceptor type 2 is associated with activation of AKT and tamoxifen resistance in breast cancer, 2015, Breast Cancer Research and Treatment, (153), 1, 31-40.

http://dx.doi.org/10.1007/s10549-015-3516-y

Copyright: Springer Verlag (Germany)

http://www.springerlink.com/?MUD=MP

Postprint available at: Linköping University Electronic Press

http://urn.kb.se/resolve?urn=urn:nbn:se:liu:diva-121133 
Loss of protein tyrosine phosphatase, non-receptor type 2 is associated with activation of AKT and tamoxifen resistance in breast cancer

Elin Karlsson ${ }^{1}$, Cynthia Veenstra ${ }^{1}$, Shad Emin ${ }^{1}$, Chhanda Dutta ${ }^{1}$, Gizeh Pérez-Tenorio ${ }^{1}$, Bo Nordenskjöld $^{1}$, Tommy Fornander ${ }^{2}$ and Olle Stå $1^{1 *}$

${ }^{1}$ Department of Clinical and Experimental Medicine, and Department of Oncology, Linköping University, SE-58185 Linköping, Sweden

${ }^{2}$ Department of Oncology, Karolinska University Hospital and Karolinska Institute, SE-17176 Stockholm, Sweden

\section{E-mail addresses}

elin.karlsson@liu.se; cynthia.veenstra@liu.se; shaem211@ @student.liu.se; chhdu589@student.liu.se; gizeh.perez-tenorio@liu.se; bo.nordenskjold@liu.se; tommy.fornander@ki.se; olle.stal@liu.se

\section{*Corresponding author}

Olle Stål, Department of Clinical and Experimental Medicine, and Department of Oncology, Linköping University, SE-58185 Linköping, Sweden

Phone: +46 010 1033491; e-mail: olle.stal@liu.se 


\begin{abstract}
Breast cancer is a heterogeneous disease and new clinical markers are needed to individualise disease management and therapy further. Alterations in the PI3K/AKT pathway, mainly PIK3CA mutations, have been shown frequently especially in the luminal breast cancer subtypes, suggesting a cross-talk between ER and PI3K/AKT. Aberrant PI3K/AKT signalling has been connected to poor response to anti-oestrogen therapies. In vitro studies have shown protein tyrosine phosphatase, non-receptor type 2 (PTPN2) as a previously unknown negative regulator of the PI3K/AKT pathway. Here, we evaluate possible genomic alterations in the PTPN2 gene and its potential as a new prognostic and treatment predictive marker for endocrine therapy benefit in breast cancer.

PTPN2 gene copy number was assessed by real-time PCR in 215 tumour samples from a treatment randomised study consisting of postmenopausal patients diagnosed with stage II breast cancer 1976-1990. Corresponding mRNA expression levels of PTPN2 were evaluated in 86 available samples by the same methodology.

Gene copy loss of PTPN2 was detected in $16 \%(34 / 215)$ of the tumours and this was significantly correlated with lower levels of PTPN2 mRNA. PTPN2 gene loss and lower mRNA levels were associated with activation of AKT and a poor prognosis. Furthermore, PTPN2 gene loss was a significant predictive marker of poor benefit from tamoxifen treatment. In conclusion, genomic loss of PTPN2 may be a previously unknown mechanism of PI3K/AKT upregulation in breast cancer. PTPN2 status is a potential new clinical marker of endocrine treatment benefit which could guide further individualised therapies in breast cancer.
\end{abstract}

Keywords: 18p, AKT, breast cancer, endocrine resistance, phosphatases, PTPN2 


\begin{abstract}
Abbreviations
v-AKT murine thymoma viral oncogene homologue (AKT), amyloid precursor protein (APP), breast cancer specific survival (BCS), cyclophosphamide-methotrexate-5-fluorouracil (CMF), distant recurrence-free survival (DRFS), epidermal growth factor receptor (EGFR), oestrogenreceptor (ER), human epidermal growth factor receptor 2 (HER2), insulin receptor (IR), Janus kinase/signal transducers and activators of transcription (JAK/STAT), phosphatidyl inositol 3kinase (PI3K), phosphatase and tensin homologue (PTEN), protein tyrosine phosphatase, nonreceptor type 2 (PTPN2), radiotherapy (RT)
\end{abstract}




\section{Introduction}

The survival rate of breast cancer is continuously increasing as a result of earlier detection and improved treatment strategies. However, in the light of a constant increase in disease incidence, breast cancer still constitutes one of the most common causes of pre-term death among women in developed countries. The high heterogeneity of breast tumours results in a need for identification of further clinically useful markers of prognosis and treatment prediction, in order to develop more individualised therapies.

The phosphatidyl inositol 3-kinase/protein kinase B/v-AKT murine thymoma viral oncogene homologue (PI3K/AKT) growth signalling pathway is essential for normal cellular homeostasis, regulating cell survival, proliferation and differentiation in response to growth factors and hormones [1]. In malignant cells, this pathway is commonly overstimulated and genetic and epigenetic alterations of the PI3K/AKT pathway are suggested as one driving cause of tumour development and progression [1,2]. In breast cancer, common aberrations include mutations in the PIK3CA and $A K T$ genes, overexpression or activation of several upstream growth factors and receptor tyrosine kinases as well as loss of function of negative regulators, e.g., the phosphatase and tensin homologue (PTEN) [2,3]. Enhanced activation of the $\mathrm{PI} 3 \mathrm{~K} / \mathrm{AKT}$ pathway has been suggested as a useful prognostic and treatment predictive factor in breast cancer. Cross-talk between PI3K/AKT and oestrogen-receptor (ER) signalling pathways has been associated with poor response to anti-oestrogen therapy [4].

The protein tyrosine phosphatase, non-receptor type 2 (PTPN2) regulates receptor tyrosine kinase signalling, through dephosphorylation of tyrosine residues thereby preventing downstream activation of intracellular pathways, among others the PI3K/AKT pathway [5,6]. The gene encoding PTPN2 is located in the chromosomal region 18p. Loss of 18p in breast tumours has previously been related to poor outcome [7] and an association between 18p deletion and decreased levels of PTPN2 mRNA has been reported [8].It may be hypothesised that loss of 18p in breast cancer could lead to decreased levels of PTPN2 and be one previously unexplored mechanism behind PI3K/AKT pathway overstimulation in breast tumours. Consequently, the aim of this study was to evaluate PTPN2 loss in a large breast cancer patient material, its possible associations to AKT-activation and its potential as a new marker of prognosis and therapy resistance in breast cancer. 


\section{Materials and methods}

\section{Patients}

The cohort used in the present study was derived from a large, randomised trial conducted by the Stockholm breast cancer group between November 1976 and April 1990, mainly aiming to evaluate the benefit from adjuvant tamoxifen treatment. The patients were randomised using a $2 \times 2$ factorial study design to receive tamoxifen for two years, or no endocrine treatment and furthermore to post-operative radiotherapy (RT) or cyclophosphamide-methotrexate-5fluorouracil (CMF)-based chemotherapy. Most of the patients in the tamoxifen arm, if diseasefree after two years, were then randomised to receive tamoxifen for three more years, or no further adjuvant treatment. Detailed information about study design and long-term follow-up data have been previously reported in detail $[9,10]$. Median follow-up time was 11 years. All patients were post-menopausal and had positive lymph nodes and/or a tumour diameter exceeding $30 \mathrm{~mm}$. Patient flow through the studies is presented in Figure 1. For PTPN2 DNA analysis, 215 tumour samples were available, whereas PTPN2 mRNA levels could be estimated in 86 samples. Retrospective studies of biomarkers were approved by the local ethics board at the Karolinska Institute, Stockholm, Sweden, and at the time, no further consent from the patients was needed. The present study was designed and presented with regard to the reporting recommendations for tumor marker prognostic studies (REMARK) guidelines [11].

\section{DNA and mRNA extraction}

DNA and total RNA were extracted from fresh-frozen tumour tissue estimated to contain $>50 \%$ cancer cells, as well as from cell lines. DNA preparation has been described previously [12]. Purified DNA was dissolved in sterile water and DNA concentration was measured using a NanoDrop ND-1000 Spectrophotometer (Thermo Fisher Scientific, Waltham, MA, USA). For subsequent analyses, the DNA was long term stored in $-70^{\circ} \mathrm{C}$.

For RNA preparations, fresh-frozen tumour tissue was homogenised with a microdismembrator (B. Braun Biotech, Germany) or a TissueLyser (Qiagen, Hilden, Germany) and total RNA was isolated with the mirVana ${ }^{\mathrm{TM}}$ miRNA isolation kit (Ambion, Austin, TX, USA) according to instructions provided by the manufacturer. Purified RNA was dissolved in nuclease-free water with addition of RNAsin ribonuclease inhibitor (Promega, Madison, WI, USA) and stored at $-70^{\circ} \mathrm{C}$. RNA integrity numbers (RIN) and concentrations were assessed 
with an Agilent 2100 Bioanalyzer (Agilent Technologies, Santa Clara, CA, USA). Only samples with RIN values $\geq 5$ were included in the analysis.

\section{Real-time PCR and microarray}

PTPN2 DNA or mRNA quantity of each sample was estimated by fast real-time PCR using an ABI Prism 7900ht (Applied Biosystems, Foster City, CA, USA). The default thermal conditions: $95^{\circ} \mathrm{C}$ for $20 \mathrm{~s} ; 40$ cycles of $95^{\circ} \mathrm{C}$ for $1 \mathrm{~s}$, and $60^{\circ} \mathrm{C}$ for $20 \mathrm{~s}$ were used for all reactions. For gene quantification, $20 \mathrm{ng}$ total DNA was added to a $10 \mu \mathrm{L}$ reaction with $1 \mathrm{x}$ Taq Man Fast Universal PCR master mix (Applied Biosystems, Foster City, CA, USA) and $0.1 \mu \mathrm{M}$ primer and probe for PTPN2 or the endogenous control Amyloid Precursor Protein $(A P P)$. APP served as endogenous control since no amplifications or deletions have been reported in breast cancer [13]. Primers and probes were designed using the software Primer Express version 1.5a (Applied Biosystems, Foster City, CA, USA). PTPN2 probes were attached to FAM and a nonfluorescent quencher (Applied Biosystems, Foster City, CA, USA) and the APP probe was coupled to the dye FAM and the quencher TAMRA (Sigma-Aldrich, St.Louis, MO, USA). Primers and probes sequences were as follows:

PTPN2 forward primer: 5'-AAGCCCACTCCGGAAACTAAA- 3', reverse primer: 5'AAACAAACAACTGTGAGGCAATCTA-3', probe: 5'-TGAGGCTCGCTAACC-3', APP forward primer: 5'-TTTGTGTGCTCTCCCAGGTCT-3', reverse prime: 5'TGGTCACTGGTTGGTTGGC-3', probe 5'-

\section{CCCTGAACTGCAGATCACCAATGTGGTAG-3’}

PTPN2 gene quantification was performed with the Comparative $\mathrm{Ct}$ method using DNA from the cell line MCF7 as the calibrator sample on each plate.

Reverse transcription of RNA was performed using the high-capacity cDNA reverse transcription kit (Applied Biosystems, Foster City, CA, USA) with 200 ng total RNA in reactions of $20 \mu \mathrm{L}$ according to manufacturer's instructions. TaqMan assays (Applied Biosystems, Foster City, CA, USA) for PTPN2 (Hs00959886_g1), and the endogenous controls MRLP19 (Hs00608519_m1) and PPIA (Hs99999901_m1) were used according to the manufacturer's instructions. Quantitative PCR was performed in duplicates with $10 \mu \mathrm{L}$ reaction volume, in 1x TaqMan fast universal master mix (Applied Biosystems Foster City, CA, USA). To confirm specificity, reactions without reverse transcriptase (-RT), as well as no template 
controls (NTC) were included on each plate. Relative PTPN2 mRNA expression levels were calculated with the Comparative Ct method, using BT-474 cDNA as the calibrator. The mean value was taken from the duplicates and for the two endogenous controls, an average value for each sample was used. For correlation analyses, expression levels of the genes were divided into four groups based on the quartiles. In the survival analyses, quartiles 1-3 (Q1-Q3) were considered as low expression and the upper quartile (Q4) as high expression.

Deletions at 18p were estimated in 25 of the samples using Affymetrix SNP Gene Copy number arrays as previously described [14].

\section{Evaluation of ER, HER2, PIK3CA and pAKT}

ER expression was determined at the time of diagnosis, before 1988 this was done using isoelectric focusing and after this year, quantitative enzyme immunoassay (EIA) was used [9,10]. Cut-off level for ER positivity was $0.05 \mathrm{fmol} / \mu \mathrm{g}$ DNA. Isoelectric focusing/EIA and IHC data have been shown to be comparable [15]. Human epidermal growth factor receptor 2 (HER2) protein was quantified retrospectively by flow cytometry as described previously [16] and HER2 amplification was determined with quantitative Real-Time PCR [17]. S-phase fraction (SPF) was previously determined by flow cytometry [18], and mutations in PIK3CA exon 9 or 20 were assessed by single-strand conformational polymorphism (SSCP) and sequencing [19]. Levels of AKT phosphorylated at S473 (pAKT) were estimated by immunohistochemistry [20]. Breast cancer subtypes were defined according to St Gallen 2011 [21] as follows: Luminal A (ER+, HER2-, SPF<12\%), Luminal B1 (ER+, HER2-, SPF $\geq 12 \%)$, Luminal B2 (ER+, HER2+), HER2-like (ER-, HER2+), and Triple-negative (ER-, HER2-), where HER2 status was defined by its gene copy number.

\section{Statistical analysis}

For estimation of relationships between different variables in two groups, Chi2 tests were used. The Kaplan-Meier product limit method was used to estimate the cumulative probabilities of distant recurrence-free survival (DRFS) or breast cancer specific survival (BCS). Differences between the curves were evaluated with the Log-rank test. For univariate and multivariate analysis of event rates, as well as interaction analysis, Cox proportional hazard regression was 
used. All statistical analyses were performed with Statistica 12.0 (Statsoft, Inc, Tulsa, OK, USA) and $\mathrm{p}<0.05$ was considered statistically significant.

\section{Results}

PTPN2 gene loss in breast cancer and decreased expression of corresponding $m R N A$.

PTPN2 gene copy number was assessed with real-time PCR in 215 breast tumours. Loss of the PTPN2 gene could be detected in 16\% (34/215) of the tumours. In 13\% (28/215) of the samples, gain of the PTPN2 gene, defined as $\geq 3$ gene copies, was found. PTPN2 gene deletion could be verified by whole genome arrays were data was available in 25 of the 215 tumours $(p=0.026)$. Real-time PCR was used to study PTPN2 mRNA expression levels in 86 available tumours. There was a significant correlation between PTPN2 gene copy number loss and low mRNA levels $(\mathrm{p}=0.038$, Table $\mathbf{1})$.

PTPN2 loss and associations with clinicopathological data and pAKT.

For PTPN2 gene copy number, no significant correlations were found to any clinicopathological data (Table 1). Since PTPN2 has been shown as a negative regulator of PI3K/AKT signalling in vitro, loss of PTPN2 was tested against pAKT levels. No significant correlation could be found in the total cohort, however in the Luminal A subgroup PTPN2 gene copy number loss was associated with strong pAKT $(\mathrm{P}=0.040$, Table 1).

Similarly, no correlations between PTPN2 mRNA and clinicopathological data were found (Table 2). However, low levels of PTPN2 mRNA were associated with strong pAKT $(\mathrm{P}=0.023)$ and absence of mutations in PIK3CA $(\mathrm{P}=0.013)$ (Table 2). The correlation to pAKT was even more apparent in the group of patients with tumours having upstream pathway activation defined by HER2+ and/or PIK3CA mutation (Table 2 and Figure 2).

PTPN2 gene loss and low mRNA-levels correlate to poor outcome 
Gene copy loss of PTPN2 was associated with a poor outcome in terms of distant recurrencefree survival as well as breast cancer survival (Figure 3 a, b). This was especially evident in the Luminal A subgroup (Figure $3 \mathbf{c}, \mathbf{d}$ ). The prognostic value of PTPN2 loss could also be confirmed in a multivariate analysis including common clinicopathological factors (Figure 3). Accordingly, low PTPN2 mRNA expression levels were associated with a poor prognosis and this was significant in a multivariate analysis (Figure 4 a). This was especially pronounced in the group of patients whose tumours harboured HER2 amplification or PIK3CA mutations compared with tumours without these aberrations (Figure 4 b, c).

The patients with tumours showing gene copy gain of PTPN2 had a similar clinical outcome as those with 2 gene copies ( $\mathrm{P}=0.74$ (DRFS), $\mathrm{P}=0.82$ (BCS)).

\section{Loss of PTPN2 is associated with tamoxifen resistance}

Overactivation of the PI3K/AKT pathway has previously been connected with cross-talk to ER signalling and subsequent endocrine resistance [4]. In the present study, patients with ERpositive breast cancer and whose tumours had deletion of the PTPN2 gene had poor benefit from tamoxifen (HR=1.90, 95\% CI 0.73-4.96) (Figure 5a) compared with the group with normal PTPN2 gene copy number (HR=0.48, 0.28-0.84) (Figure 5b). The interaction between tamoxifen treatment benefit and PTPN2 genomic loss was significant $(\mathrm{p}=0.011)$.

\section{Discussion}

The present study suggests the phosphatase PTPN2 as a tumour suppressor gene and a new potential clinical marker in breast cancer. Loss of PTPN2 may be a previously unexplored mechanism for upregulation of the PI3K/AKT pathway in vivo.

The post-translational modifications mediated by the balance between protein tyrosine kinases and protein tyrosine phosphatases (PTPs), regulate the activity of numerous essential biological processes. Consequently, an imbalance between these factors is suggested to be involved in several human diseases [22]. The protein phosphatase PTPN2 was first isolated in T-cells by Cool et al. in 1989 [23], thereby referred to as T-cell protein tyrosine phosphatase (TCPTP). Later, the gene was mapped to the chromosomal region 18p11.3-p11.2 [24,25]. Three splicing 
variants of the gene have been reported, resulting in three different isoforms of the protein, differing in their C-termini [26]. The difference is assumed to determine substrate specificity as well as cellular locations of the proteins. PTPN2 is ubiquitously expressed and has been shown able to regulate the activity of several receptor tyrosine kinases, including the insulin receptor (IR), the epidermal growth factor receptor (EGFR), vascular endothelial growth factor receptor (VEGFR) and the hepatocyte growth factor receptor (HGFR/Met) [6,27-31]. In normal intestinal epithelial cells, PTPN2 has been shown to regulate cytokine and chloride secretion through EGFR and TNF $\alpha$-signalling [32,33]. Upregulation of PTPN2 and the 72\% homologues phosphatase PTP1B has been associated with altered glucose homeostasis and development of diabetes through inhibition of IR signalling [34].

Loss of the 18p chromosomal region has been shown as an early event in breast cancer progression [35] and has been associated with a poor outcome [7]. Addou-Klouche et al. identified PTPN2 as one candidate tumour suppressor gene in this region and showed a correlation between PTPN2 gene loss and low mRNA expression levels [8]. In the present study, we confirm the correlation between PTPN2 gene deletion and low mRNA expression levels in a breast cancer material. In addition, this was associated with a poor outcome. Downregulation of PTPN2 has been previously shown in different types of cancer. In hepatocellular carcinoma, loss of PTPN2 was correlated with presence of lymph node metastasis [36]. PTPN2 loss through gene deletions or mutations have been reported in T-cell acute lymphoblastic leukaemia (T-ALL) and peripheral T-cell lymphoma not otherwise specified, and has been coupled to increased cytokine sensitivity and proliferation through stimulation of the Janus kinase/signal transducers and activators of transcription (JAK/STAT) -signalling pathways [37-39]. There are few functional studies conducted on PTPN2 in breast cancer cells, however, in triple-negative breast cancers PTPN2 downregulation and subsequent upregulation of SFK (Src family of protein tyrosine kinases) and STAT3-signalling was detected [40,41]. In vitro studies on other cell types, including glioblastoma cells, have shown PTPN2 as a negative regulator of receptor tyrosine kinases (RTKs), by dephosphorylating tyrosine residues [5,6,29]. Aberrant activation of RTKs is assumed to drive proliferation and growth in a large proportion of breast cancers. Therefore, a role for PTPN2 in this context is plausible.

In non-small cell lung cancer cells, inhibition of PTPN2 was shown to promote increased phosphorylation of AKT in the presence, but not in the absence of RAS-mutations [30]. Here, we show a correlation between low PTPN2 mRNA levels and high expression of pAKT, in 
particular in the presence of upstream pathway stimulation by $H E R 2$ amplification and/or PIK3CA mutations. In addition, PTPN2 loss was associated with pAKT in the Luminal A subtype. Tumours of this subtype are in general hormone responsive with low proliferation rate and associated with a relatively good prognosis. Alterations in the PI3K/AKT pathway, mainly PIK3CA mutations, have been shown most frequent in the luminal subtypes, suggesting a crosstalk between ER and PI3K/AKT [3]. Aberrant PI3K/AKT signalling has been connected to poor response to anti-oestrogen therapies in several studies [20,42-50]. In the present study, we showed PTPN2 gene loss as a new potential marker of endocrine resistance. This finding needs to be confirmed in independent cohorts and furthermore it would be interesting to investigate if it is also relevant for treatment with aromatase inhibitors. In the light of its role as a tumour suppressor, agonists activating PTPN2 are under development and have been shown to inhibit RTK signalling effectively in vitro [51]. One may suggest that PTPN2 agonists could be useful in combination with endocrine therapies in the group of patients described above.

Although a significant correlation was found between PTPN2 gene loss and mRNA expression levels, the prognostic value of these aberrations was shown mainly in separate tumour subtypes. The involvement of several co-deleted genes in the $18 \mathrm{p}$ region may be one explanation. The presence of several PTPN2 isoforms could also obstruct the interpretation. Previous studies have suggested the nuclear PTPN2 isoform referred to as TC45 as mostly involved in tumourigenesis $[29,34,41,52]$. The expression assays used in the present study detect all known splicing variants and do not distinguish between them. In a future study, isoform-specific analysis of PTPN2 would be valuable to give further insight in their possible different oncogenic roles.

In conclusion, this study demonstrates genomic and transcriptomic loss of PTPN2 as a new possible mechanism for PI3K/AKT upregulation in breast cancer. PTPN2 may be a potential clinical marker of prognosis and endocrine treatment prediction, thus allowing further tailored patient therapies.

\section{Acknowledgements}

This work was supported by grants from The Swedish Cancer Society (\#13 0435) and The Swedish Research Council (A0346701).

\section{Ethical standards}


The experiments comply with the current laws of Sweden

\section{Conflict of interest}

The authors declare that they have no conflict of interest 


\section{References}

1. Hers I, Vincent EE, Tavare JM (2011) Akt signalling in health and disease. Cellular signalling 23 (10):1515-1527. doi:10.1016/j.cellsig.2011.05.004

2. Fruman DA, Rommel C (2014) PI3K and cancer: lessons, challenges and opportunities. Nature reviews Drug discovery 13 (2):140-156. doi:10.1038/nrd4204

3. Miller TW, Rexer BN, Garrett JT, Arteaga CL (2011) Mutations in the phosphatidylinositol 3-kinase pathway: role in tumor progression and therapeutic implications in breast cancer. Breast Cancer Res 13 (6):224. doi:10.1186/bcr3039

4. Miller TW, Balko JM, Arteaga CL (2011) Phosphatidylinositol 3-kinase and antiestrogen resistance in breast cancer. Journal of clinical oncology : official journal of the American Society of Clinical Oncology 29 (33):4452-4461. doi:10.1200/JCO.2010.34.4879

5. Klingler-Hoffmann M, Fodero-Tavoletti MT, Mishima K, Narita Y, Cavenee WK, Furnari FB, Huang HJ, Tiganis T (2001) The protein tyrosine phosphatase TCPTP suppresses the tumorigenicity of glioblastoma cells expressing a mutant epidermal growth factor receptor. J Biol Chem 276 (49):46313-46318. doi:10.1074/jbc.M106571200

6. Tiganis T, Kemp BE, Tonks NK (1999) The protein-tyrosine phosphatase TCPTP regulates epidermal growth factor receptor-mediated and phosphatidylinositol 3-kinase-dependent signaling. J Biol Chem 274 (39):27768-27775

7. Climent J, Martinez-Climent JA, Blesa D, Garcia-Barchino MJ, Saez R, Sanchez-Izquierdo D, Azagra

P, Lluch A, Garcia-Conde J (2002) Genomic loss of 18p predicts an adverse clinical outcome in patients with high-risk breast cancer. Clinical cancer research : an official journal of the American Association for Cancer Research 8 (12):3863-3869

8. Addou-Klouche L, Adelaide J, Finetti P, Cervera N, Ferrari A, Bekhouche I, Sircoulomb F, Sotiriou C, Viens P, Moulessehoul S, Bertucci F, Birnbaum D, Chaffanet M (2010) Loss, mutation and deregulation of L3MBTL4 in breast cancers. Molecular cancer 9:213. doi:10.1186/1476-4598-9-213 9. Rutqvist LE, Johansson H (2006) Long-term follow-up of the Stockholm randomized trials of postoperative radiation therapy versus adjuvant chemotherapy among 'high risk' pre- and postmenopausal breast cancer patients. Acta oncologica 45 (5):517-527. doi:10.1080/02841860600702068

10. Rutqvist LE, Johansson H, Stockholm Breast Cancer Study G (2007) Long-term follow-up of the randomized Stockholm trial on adjuvant tamoxifen among postmenopausal patients with early stage breast cancer. Acta oncologica 46 (2):133-145. doi:10.1080/02841860601034834

11. McShane LM, Altman DG, Sauerbrei W, Taube SE, Gion M, Clark GM, Statistics Subcommittee of NCIEWGoCD (2006) REporting recommendations for tumor MARKer prognostic studies (REMARK). Breast Cancer Res Treat 100 (2):229-235. doi:10.1007/s10549-006-9242-8

12. Askmalm MS, Carstensen J, Nordenskjöld B, Olsson B, Rutqvist LE, Skoog L, Stål O (2004) Mutation and accumulation of $\mathrm{p} 53$ related to results of adjuvant therapy of postmenopausal breast cancer patients. Acta oncologica 43 (3):235-244

13. Bieche I, Olivi M, Champeme MH, Vidaud D, Lidereau R, Vidaud M (1998) Novel approach to quantitative polymerase chain reaction using real-time detection: application to the detection of gene amplification in breast cancer. International journal of cancer Journal international du cancer 78 (5):661-666

14. Karlsson E, Waltersson MA, Bostner J, Perez-Tenorio G, Olsson B, Hallbeck AL, Stål O (2011) Highresolution genomic analysis of the 11q13 amplicon in breast cancers identifies synergy with 8p12 amplification, involving the mTOR targets S6K2 and 4EBP1. Genes, chromosomes \& cancer 50 (10):775-787. doi:10.1002/gcc.20900

15. Khoshnoud MR, Löfdahl B, Fohlin H, Fornander T, Stål O, Skoog L, Bergh J, Nordenskjöld B (2011) Immunohistochemistry compared to cytosol assays for determination of estrogen receptor and 
prediction of the long-term effect of adjuvant tamoxifen. Breast Cancer Res Treat 126 (2):421-430. doi:10.1007/s10549-010-1202-7

16. Stål O, Sullivan S, Sun XF, Wingren S, Nordenskjöld B (1994) Simultaneous analysis of c-erbB-2 expression and DNA content in breast cancer using flow cytometry. Cytometry 16 (2):160-168. doi:10.1002/cyto.990160210

17. Gunnarsson C, Ahnström M, Kirschner K, Olsson B, Nordenskjöld B, Rutqvist LE, Skoog L, Stål O (2003) Amplification of HSD17B1 and ERBB2 in primary breast cancer. Oncogene 22 (1):34-40. doi:10.1038/sj.onc.1206078

18. Stål O, Sullivan S, Wingren S, Skoog L, Rutqvist LE, Carstensen JM, Nordenskjöld B (1995) c-erbB-2 expression and benefit from adjuvant chemotherapy and radiotherapy of breast cancer. European journal of cancer 31A (13-14):2185-2190

19. Perez-Tenorio G, Alkhori L, Olsson B, Waltersson MA, Nordenskjöld B, Rutqvist LE, Skoog L, Stål O (2007) PIK3CA mutations and PTEN loss correlate with similar prognostic factors and are not mutually exclusive in breast cancer. Clinical cancer research : an official journal of the American Association for Cancer Research 13 (12):3577-3584. doi:13/12/3577 [pii]

10.1158/1078-0432.CCR-06-1609

20. Stål O, Perez-Tenorio G, Åkerberg L, Olsson B, Nordenskjöld B, Skoog L, Rutqvist LE (2003) Akt kinases in breast cancer and the results of adjuvant therapy. Breast Cancer Res 5 (2):R37-44 21. Goldhirsch A, Wood WC, Coates AS, Gelber RD, Thurlimann B, Senn HJ (2011) Strategies for subtypes--dealing with the diversity of breast cancer: highlights of the St. Gallen International Expert Consensus on the Primary Therapy of Early Breast Cancer 2011. Annals of oncology : official journal of the European Society for Medical Oncology / ESMO 22 (8):1736-1747. doi:mdr304 [pii] 10.1093/annonc/mdr304

22. Dube N, Tremblay ML (2005) Involvement of the small protein tyrosine phosphatases TC-PTP and PTP1B in signal transduction and diseases: from diabetes, obesity to cell cycle, and cancer.

Biochimica et biophysica acta 1754 (1-2):108-117. doi:10.1016/j.bbapap.2005.07.030

23. Cool DE, Tonks NK, Charbonneau H, Walsh KA, Fischer EH, Krebs EG (1989) cDNA isolated from a human T-cell library encodes a member of the protein-tyrosine-phosphatase family. Proc Natl Acad Sci U S A 86 (14):5257-5261

24. Johnson CV, Cool DE, Glaccum MB, Green N, Fischer EH, Bruskin A, Hill DE, Lawrence JB (1993) Isolation and mapping of human T-cell protein tyrosine phosphatase sequences: localization of genes and pseudogenes discriminated using fluorescence hybridization with genomic versus CDNA probes. Genomics 16 (3):619-629. doi:10.1006/geno.1993.1239

25. Sakaguchi AY, Sylvia VL, Martinez L, Smith EA, Han ES, Lalley PA, Shows TB, Choudhury GG (1992) Assignment of tyrosine-specific T-cell phosphatase to conserved syntenic groups on human chromosome 18 and mouse chromosome 18. Genomics 12 (1):151-154

26. Bussieres-Marmen S, Hutchins AP, Schirbel A, Rebert N, Tiganis T, Fiocchi C, Miranda-Saavedra D, Tremblay ML (2014) Characterization of PTPN2 and its use as a biomarker. Methods 65 (2):239-246. doi:10.1016/j.ymeth.2013.08.020

27. Galic S, Hauser C, Kahn BB, Haj FG, Neel BG, Tonks NK, Tiganis T (2005) Coordinated regulation of insulin signaling by the protein tyrosine phosphatases PTP1B and TCPTP. Mol Cell Biol 25 (2):819829. doi:10.1128/MCB.25.2.819-829.2005

28. Galic S, Klingler-Hoffmann M, Fodero-Tavoletti MT, Puryer MA, Meng TC, Tonks NK, Tiganis T (2003) Regulation of insulin receptor signaling by the protein tyrosine phosphatase TCPTP. Mol Cell Biol 23 (6):2096-2108

29. Mattila E, Auvinen K, Salmi M, Ivaska J (2008) The protein tyrosine phosphatase TCPTP controls VEGFR2 signalling. Journal of cell science 121 (Pt 21):3570-3580. doi:10.1242/jcs.031898

30. Omerovic J, Clague MJ, Prior IA (2010) Phosphatome profiling reveals PTPN2, PTPRJ and PTEN as potent negative regulators of PKB/Akt activation in Ras-mutated cancer cells. Biochem J 426 (1):6572. doi:10.1042/BJ20091413 
31. Tiganis T, Bennett AM, Ravichandran KS, Tonks NK (1998) Epidermal growth factor receptor and the adaptor protein $\mathrm{p} 52 \mathrm{Shc}$ are specific substrates of T-cell protein tyrosine phosphatase. Mol Cell Biol 18 (3):1622-1634

32. Scharl M, McCole DF, Weber A, Vavricka SR, Frei P, Kellermeier S, Pesch T, Fried M, Rogler G (2011) Protein tyrosine phosphatase N2 regulates TNFalpha-induced signalling and cytokine secretion in human intestinal epithelial cells. Gut 60 (2):189-197. doi:10.1136/gut.2010.216606 33. Scharl M, Rudenko I, McCole DF (2010) Loss of protein tyrosine phosphatase N2 potentiates epidermal growth factor suppression of intestinal epithelial chloride secretion. American journal of physiology Gastrointestinal and liver physiology 299 (4):G935-945. doi:10.1152/ajpgi.00106.2010 34. Tiganis T (2013) PTP1B and TCPTP--nonredundant phosphatases in insulin signaling and glucose homeostasis. The FEBS journal 280 (2):445-458. doi:10.1111/j.1742-4658.2012.08563.x

35. Kittiniyom K, Gorse KM, Dalbegue F, Lichy JH, Taubenberger JK, Newsham IF (2001) Allelic loss on chromosome band 18p11.3 occurs early and reveals heterogeneity in breast cancer progression. Breast Cancer Res 3 (3):192-198

36. Lee CF, Ling ZQ, Zhao T, Fang SH, Chang WC, Lee SC, Lee KR (2009) Genomic-wide analysis of lymphatic metastasis-associated genes in human hepatocellular carcinoma. World journal of gastroenterology : WJG 15 (3):356-365

37. Kleppe M, Lahortiga I, El Chaar T, De Keersmaecker K, Mentens N, Graux C, Van Roosbroeck K, Ferrando AA, Langerak AW, Meijerink JP, Sigaux F, Haferlach T, Wlodarska I, Vandenberghe P, Soulier J, Cools J (2010) Deletion of the protein tyrosine phosphatase gene PTPN2 in T-cell acute lymphoblastic leukemia. Nature genetics 42 (6):530-535. doi:10.1038/ng.587

38. Kleppe M, Soulier J, Asnafi V, Mentens N, Hornakova T, Knoops L, Constantinescu S, Sigaux F, Meijerink JP, Vandenberghe P, Tartaglia M, Foa R, Macintyre E, Haferlach T, Cools J (2011) PTPN2 negatively regulates oncogenic JAK1 in T-cell acute lymphoblastic leukemia. Blood 117 (26):70907098. doi:10.1182/blood-2010-10-314286

39. Kleppe M, Tousseyn T, Geissinger E, Kalender Atak Z, Aerts S, Rosenwald A, Wlodarska I, Cools J (2011) Mutation analysis of the tyrosine phosphatase PTPN2 in Hodgkin's lymphoma and T-cell nonHodgkin's lymphoma. Haematologica 96 (11):1723-1727. doi:10.3324/haematol.2011.041921 40. Shields BJ, Court NW, Hauser C, Bukczynska PE, Tiganis T (2008) Cell cycle-dependent regulation of SFK, JAK1 and STAT3 signalling by the protein tyrosine phosphatase TCPTP. Cell cycle 7 (21):34053416

41. Shields BJ, Wiede F, Gurzov EN, Wee K, Hauser C, Zhu HJ, Molloy TJ, O'Toole SA, Daly RJ, Sutherland RL, Mitchell CA, McLean CA, Tiganis T (2013) TCPTP regulates SFK and STAT3 signaling and is lost in triple-negative breast cancers. Mol Cell Biol 33 (3):557-570. doi:10.1128/MCB.01016-12 42. Beelen K, Zwart W, Linn SC (2012) Can predictive biomarkers in breast cancer guide adjuvant endocrine therapy? Nature reviews Clinical oncology 9 (9):529-541. doi:10.1038/nrclinonc.2012.121 43. Droog M, Beelen K, Linn S, Zwart W (2013) Tamoxifen resistance: From bench to bedside. European journal of pharmacology 717 (1-3):47-57. doi:10.1016/j.ejphar.2012.11.071 44. Schiff R, Massarweh SA, Shou J, Bharwani L, Mohsin SK, Osborne CK (2004) Cross-talk between estrogen receptor and growth factor pathways as a molecular target for overcoming endocrine resistance. Clinical cancer research : an official journal of the American Association for Cancer Research 10 (1 Pt 2):331S-336S

45. Beelen K, Opdam M, Severson TM, Koornstra RH, Vincent AD, Wesseling J, Muris JJ, Berns EM, Vermorken JB, van Diest PJ, Linn SC (2014) PIK3CA mutations, phosphatase and tensin homolog, human epidermal growth factor receptor 2 and insulin-like growth factor 1 receptor and adjuvant tamoxifen resistance in postmenopausal breast cancer patients. Breast Cancer Res 16 (1):R13. doi:10.1186/bcr3606

46. Beelen K, Opdam M, Severson TM, Koornstra RH, Vincent AD, Wesseling J, Muris JJ, Berns EM, Vermorken JB, van Diest PJ, Linn SC (2014) Phosphorylated p-70S6K predicts tamoxifen resistance in postmenopausal breast cancer patients randomized between adjuvant tamoxifen versus no systemic treatment. Breast Cancer Res 16 (1):R6. doi:10.1186/bcr3598 
47. Bostner J, Ahnström Waltersson M, Fornander T, Skoog L, Nordenskjöld B, Stål O (2007) Amplification of CCND1 and PAK1 as predictors of recurrence and tamoxifen resistance in postmenopausal breast cancer. Oncogene 26 (49):6997-7005. doi:10.1038/sj.onc.1210506 48. Bostner J, Karlsson E, Pandiyan MJ, Westman H, Skoog L, Fornander T, Nordenskjöld B, Stål O (2013) Activation of Akt, mTOR, and the estrogen receptor as a signature to predict tamoxifen treatment benefit. Breast Cancer Res Treat 137 (2):397-406. doi:10.1007/s10549-012-2376-y 49. Karlsson E, Perez-Tenorio G, Amin R, Bostner J, Skoog L, Fornander T, Sgroi DC, Nordenskjöld B, Hallbeck AL, Stål O (2013) The mTOR effectors 4EBP1 and S6K2 are frequently coexpressed, and associated with a poor prognosis and endocrine resistance in breast cancer: a retrospective study including patients from the randomised Stockholm tamoxifen trials. Breast Cancer Res 15 (5):R96. doi:10.1186/bcr3557

50. Perez-Tenorio G, Stål O, Southeast Sweden Breast Cancer G (2002) Activation of AKT/PKB in breast cancer predicts a worse outcome among endocrine treated patients. British journal of cancer 86 (4):540-545. doi:10.1038/sj.bjc.6600126

51. Mattila E, Marttila H, Sahlberg N, Kohonen P, Tahtinen S, Halonen P, Perala M, Ivaska J (2010) Inhibition of receptor tyrosine kinase signalling by small molecule agonist of T-cell protein tyrosine phosphatase. BMC cancer 10:7. doi:10.1186/1471-2407-10-7

52. Tiganis $T$ (2002) Protein tyrosine phosphatases: dephosphorylating the epidermal growth factor receptor. IUBMB life 53 (1):3-14. doi:10.1080/15216540210811 
Table 1. Correlations between PTPN2 gene copy loss and clinicopathological data.

\begin{tabular}{|c|c|c|c|}
\hline & & yene copies & \\
\hline & Deletion & Two or more copies & $P$-value \\
\hline Tamoxife & & & \\
\hline No & $16(14.6)$ & $94(85.5)$ & $\mathrm{P}=0.60$ \\
\hline Yes & $18(17.1)$ & 87 (82.9) & \\
\hline RT/CMF & & & \\
\hline RT & $15(15.5)$ & $82(84.5)$ & $\mathrm{P}=0.90$ \\
\hline CMF & $19(16.1)$ & $99(83.9)$ & \\
\hline Lymph n & & & \\
\hline Negative & $3(13.6)$ & $19(86.4)$ & $\mathrm{P}=0.77$ \\
\hline Positive & $31(16.1)$ & $162(83.9)$ & \\
\hline Tumour & & & \\
\hline$\leq 20 \mathrm{~mm}$ & $14(16.3)$ & $72(83.7)$ & $\mathrm{P}=0.88$ \\
\hline$>20 \mathrm{~mm}$ & $20(15.5)$ & $109(84.5)$ & \\
\hline S-phase f & & & \\
\hline$<12 \%$ & $20(13.9)$ & $124(86.1)$ & $\mathrm{P}=0.18$ \\
\hline$\geq 12 \%$ & $11(22.0)$ & $39(78.0)$ & \\
\hline ER & & & \\
\hline Negative & $10(16.4)$ & $51(83.6)$ & $\mathrm{P}=0.93$ \\
\hline Positive & $24(15.9)$ & $127(84.1)$ & \\
\hline HER2 ge & & & \\
\hline Negative & $24(15.2)$ & $134(84.8)$ & $\mathrm{P}=0.80$ \\
\hline Positive & $6(13.6)$ & $38(86.4)$ & \\
\hline HER2 pr & & & \\
\hline Negative & $23(15.2)$ & $128(84.8)$ & $\mathrm{P}=0.96$ \\
\hline Positive & $9(15.5)$ & $49(84.5)$ & \\
\hline PIK3CA & & & \\
\hline- & $25(15.6)$ & $135(84.4)$ & $\mathrm{P}=0.78$ \\
\hline+ & $9(17.3)$ & $43(82.7)$ & \\
\hline pAKT (A & & & \\
\hline$\leq 10 \%$ & $22(14.2)$ & $133(85.8)$ & $\mathrm{P}=0.21$ \\
\hline$>10 \%$ & $12(21.4)$ & $44(78.6)$ & \\
\hline pAKT (L & & & \\
\hline$\leq 10 \%$ & $7(9.9)$ & $64(90.1)$ & $P=0.040$ \\
\hline$>10 \%$ & $6(27.3)$ & $16(72.7)$ & \\
\hline PTPN2 n & & & \\
\hline Low & $10(20.4)$ & $39(79.6)$ & $\mathbf{P}=0.038 *$ \\
\hline High & $0(0)$ & $18(100)$ & \\
\hline
\end{tabular}


Table 2. Correlations between PTPN2 mRNA levels and clinicopathological data.

\begin{tabular}{|c|c|c|c|}
\hline & \multicolumn{3}{|c|}{ PTPN2 mRNA expression $n(\%)$} \\
\hline & Low $(Q 1-Q 3)$ & $\operatorname{High}(Q 4)$ & $p$-value \\
\hline \multicolumn{4}{|c|}{ Tamoxifen treated } \\
\hline No & $23(67.7)$ & $11(32.4)$ & $\mathrm{p}=0.17$ \\
\hline Yes & $42(80.8)$ & $10(19.2)$ & \\
\hline \multicolumn{4}{|l|}{ RT/CMF } \\
\hline RT & $27(71.1)$ & $11(29.0)$ & $\mathrm{p}=0.38$ \\
\hline CMF & $38(79.2)$ & $10(20.8)$ & \\
\hline \multicolumn{4}{|c|}{ Lymph node status } \\
\hline Negative & $6(100)$ & $0(0)$ & $\mathrm{p}=0.15$ \\
\hline Positive & $59(73.8)$ & $21(26.3)$ & \\
\hline \multicolumn{4}{|c|}{ Tumor Size } \\
\hline$\leq 20 \mathrm{~mm}$ & $29(78.4)$ & $8(21.6)$ & $\mathrm{p}=0.60$ \\
\hline$>20 \mathrm{~mm}$ & $36(73.5)$ & $13(26.5)$ & \\
\hline \multicolumn{4}{|c|}{ S-phase fraction } \\
\hline$<12 \%$ & $37(69.8)$ & $16(30.2)$ & $\mathrm{p}=0.30$ \\
\hline$\geq 12 \%$ & $21(80.8)$ & $5(19.2)$ & \\
\hline \multicolumn{4}{|l|}{ ER } \\
\hline negative & $16(80.0)$ & $4(20.0)$ & $p=0.60$ \\
\hline positive & $49(74.2)$ & $17(25.8)$ & \\
\hline \multicolumn{4}{|c|}{ HER2 gene amplification } \\
\hline negative & $50(76.9)$ & $15(23.1)$ & $\mathrm{p}=0.50$ \\
\hline positive & $11(68.8)$ & $5(31.3)$ & \\
\hline \multicolumn{4}{|c|}{ HER2 protein } \\
\hline negative & $50(76.9)$ & $15(23.1)$ & $p=0.53$ \\
\hline positive & $14(70.0)$ & $6(30.0)$ & \\
\hline \multicolumn{4}{|c|}{ PIK3CA mutation } \\
\hline- & $54(80.6)$ & $13(19.4)$ & $p=0.019$ \\
\hline+ & $9(52.9)$ & $8(47.1)$ & \\
\hline \multicolumn{4}{|c|}{ pAKT (All patients) } \\
\hline$\leq 10 \%$ & $38(67.9)$ & $18(32.1)$ & $p=0.023$ \\
\hline$>10 \%$ & $27(90.0)$ & $3(10.0)$ & \\
\hline \multicolumn{4}{|c|}{$\begin{array}{l}\text { pAKT } \\
(H E R 2+\text { and/or PIK3CA+) }\end{array}$} \\
\hline$\leq 10 \%$ & $8(42.1)$ & $11(57.9)$ & $p=0.0058$ \\
\hline$>10 \%$ & $11(91.7)$ & $1(8.3)$ & \\
\hline
\end{tabular}




\section{Figure legends}

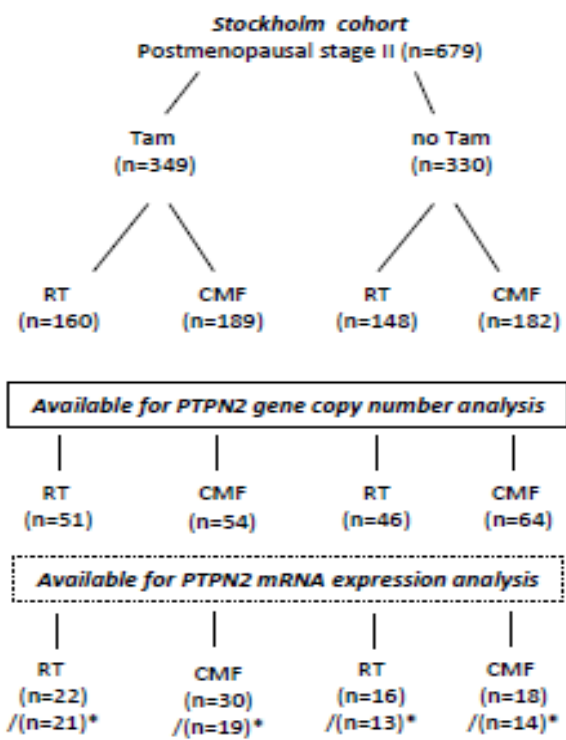

Figure 1

Figure 1. Patient flow through the study. (Tam: tamoxifen, RT: radiotherapy, CMF: cyclophosphamide, metotrexate, 5-fluorouracil chemotherapy, TMA: tissue microarray, IHC: immunohistochemistry, *data available for both DNA and mRNA). 

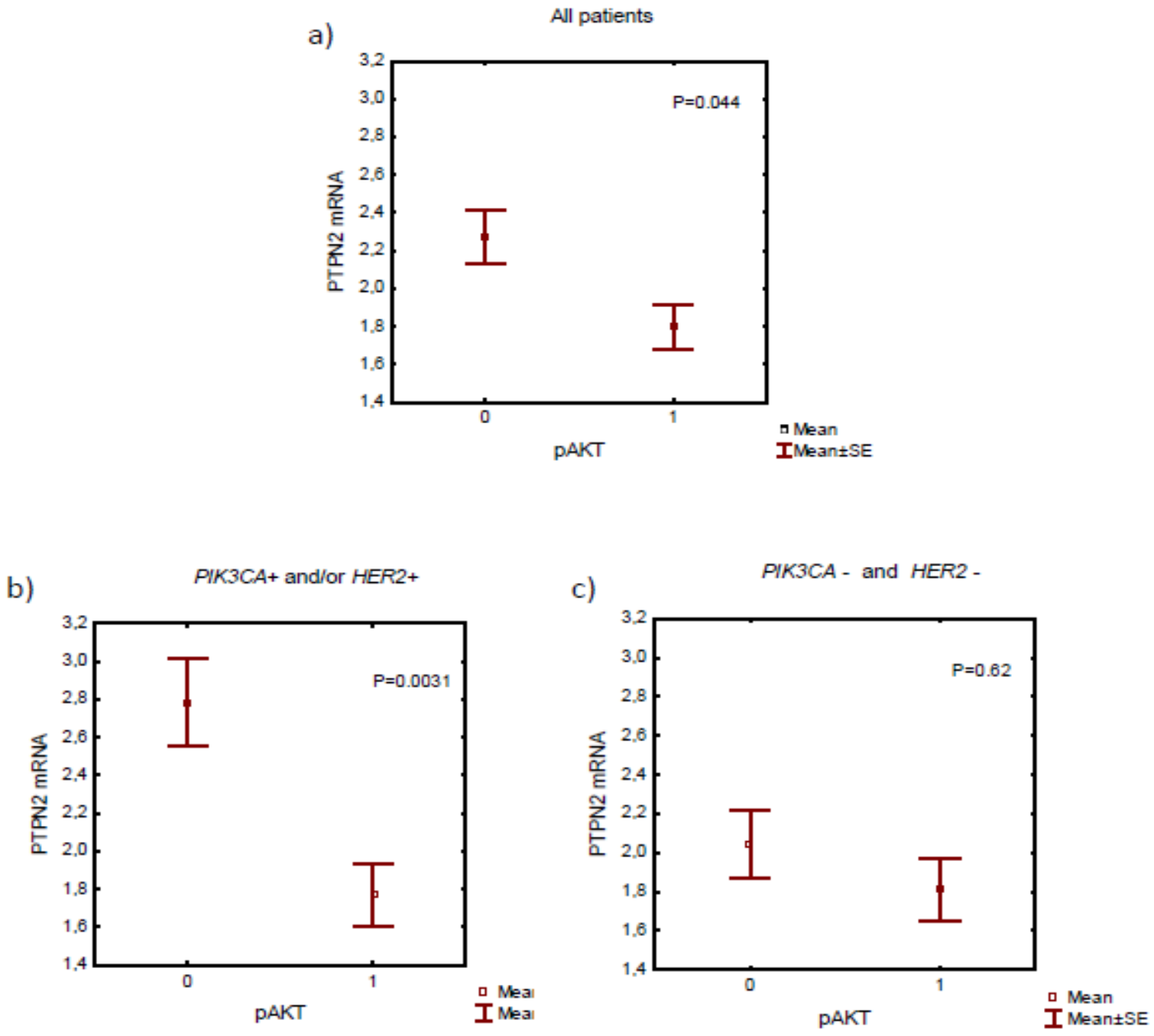

Figure 2

Figure 2. Mean plot of PTPN2 mRNA (continuous values) in relation to pAKT_S473 protein expression status in all patients (a), the subgroup of patients with tumours harboring 
PI3K mutation and/or HER2 amplification (b) or no PI3K mutation or HER2 amplification (c). P-values refer to the Kruska-Wallis test.

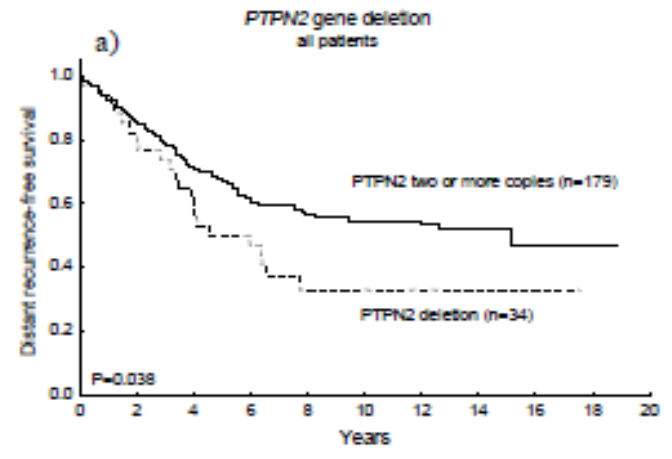

DRFS: $H R(95 \% \mathrm{CI})=1.73(1.05-2.84), \mathrm{p}=0.031$

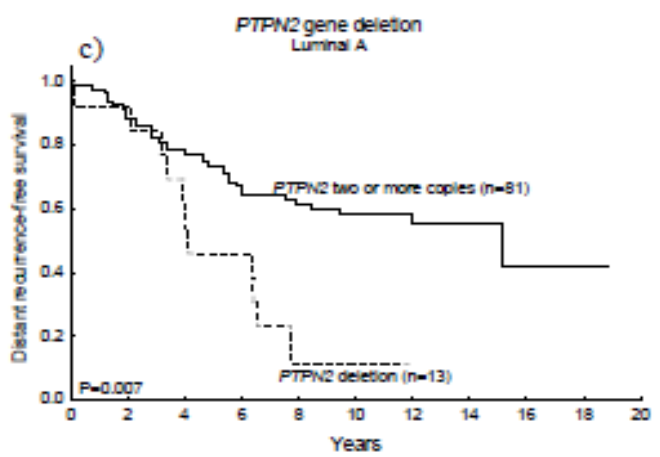

DRFS: $H R(95 \% \mathrm{CI})=2.52(1.21-5.22), \mathrm{p}=0.013$

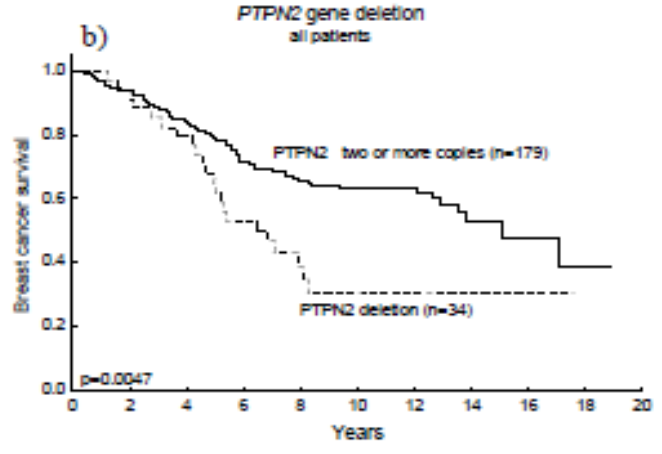

BCS: $\mathrm{HR}(95 \% \mathrm{CI})=2.23(1.34-3.72), \mathrm{p}=0.0020$

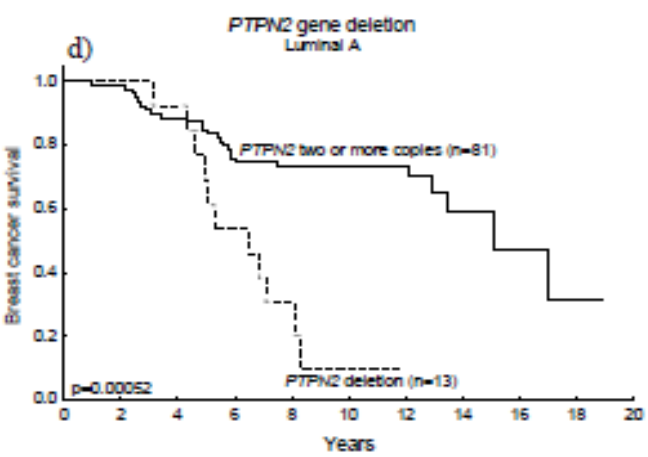

BCS: HR $(95 \% \mathrm{CI})=4.04(1.87-8.69), \mathrm{p}=0.00036$

Figure 3 
Figure 3. Univariate and multivariate analysis of distant recurrence-free survival (DRFS) $(\mathrm{a}, \mathrm{c})$ and breast cancer survival (BCS) (b, d) in relation to PTPN2 gene copy number loss in the Stockholm cohort. All patients (a, b), Luminal A subtype (c, d). The Cox analysis included the following variables: adjuvant chemotherapy treatment, endocrine treatment, lymph node status, tumour size, and when all patients were included $(a, b)$ also HER2 and ER status.

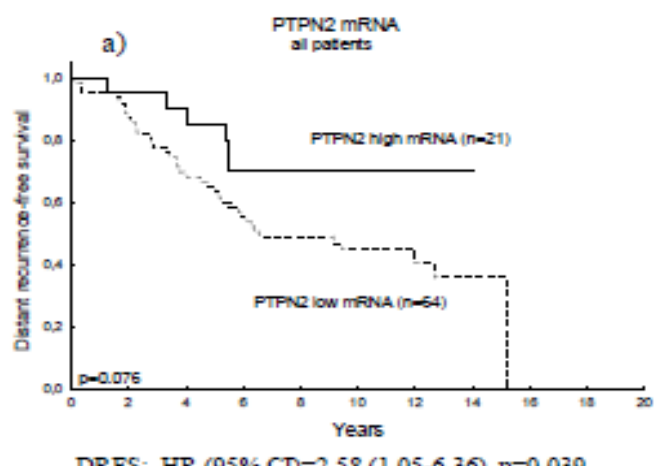

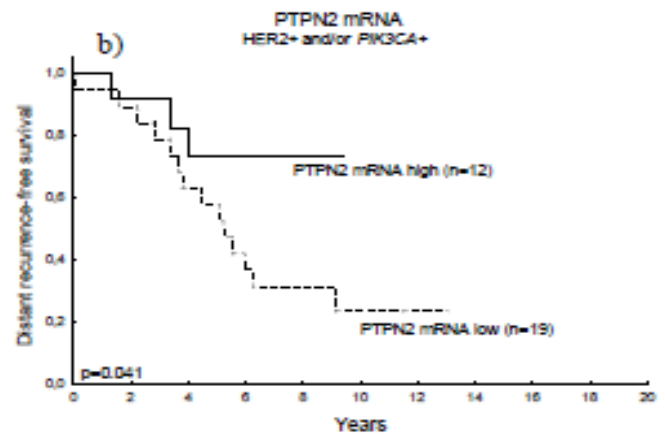

DRFS: $H R(95 \% \mathrm{CI})=3.85(0.96-15.39), \mathrm{p}=0.057$

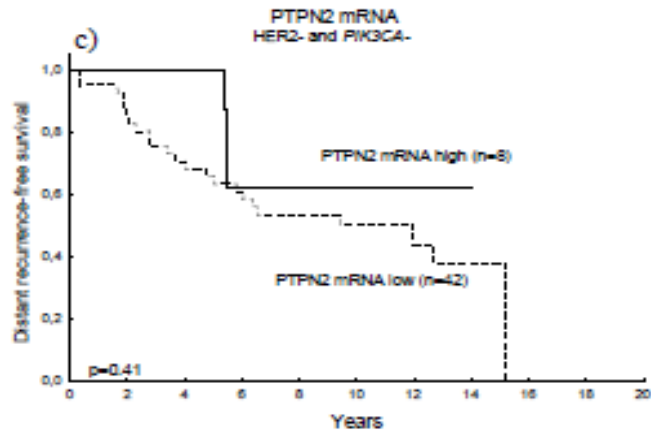

DRFS: HR $(95 \% \mathrm{CI})=1.69(0.47-6.08), \mathrm{p}=0.42$

Figure 4 
Figure 4. Univariate and multivariate analysis of distant recurrence-free survival (DRFS) in relation to PTPN2 mRNA expression levels in the Stockholm cohort, all patients (a), HER2+ and/or PIK3CA+ (b) and HER2- and PIK3CA- (c). The Cox analysis included the following variables: adjuvant chemotherapy treatment, endocrine treatment, lymph node status, tumour size, HER2 (a) and ER status. 

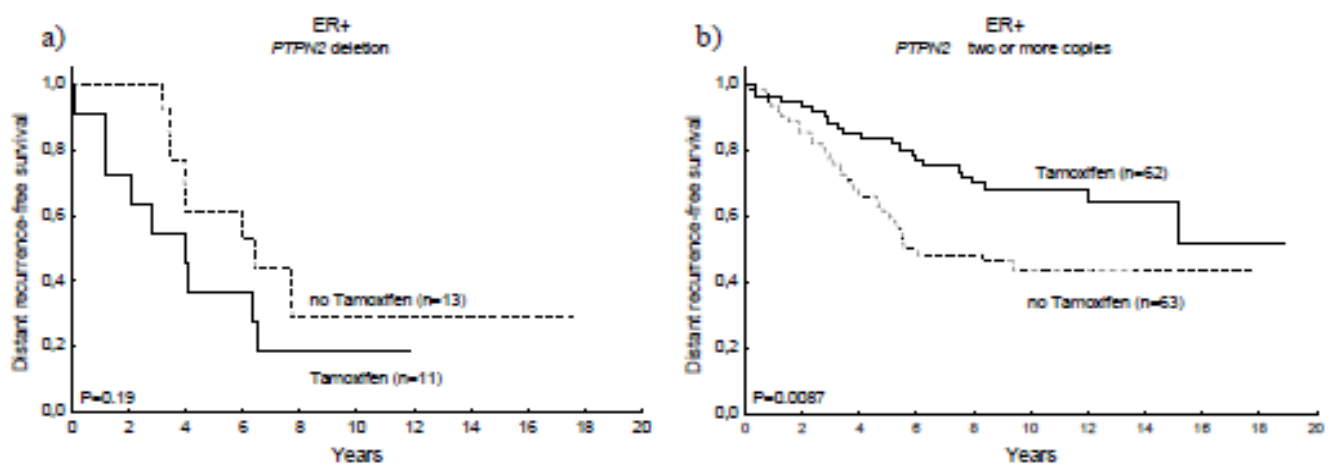

Figure 5

Figure 5. Distant recurrence-free survival (DRFS) in relation to tamoxifen treatment in the group with PTPN2 gene deletion (a) and two or more PTPN2 gene copies (b) in the Stockholm cohort. 